\section{§3. Tritium Control for Flibe/V-alloy Blanket System}

Muroga, T., Sagara, A., Tanaka, T.

Reduced Activation Ferritic/Martensitic Steel (RAFM) and molten salt Flibe was used in FFHR blanket design. On the other hand, the use of vanadium alloys $(\mathrm{V}-4 \mathrm{Cr}-4 \mathrm{Ti})$ can increase the maximum operation temperature and $\Delta \mathrm{T}$ of the coolant Flibe in the blanket, which is significantly beneficial for reducing viscosity of the fluid and enhancing thermal efficiency of the plant.

However, combination of high partial pressure of $T_{2}$ in Flibe and high tritium solubility of V-alloy structure would result in large tritium inventory in the blanket structural components. As a solution to this issue, it was proposed to dope $\mathrm{MoF}_{6}$ or $\mathrm{WF}_{6}$ into Flibe for corrosion protection of the wall surfaces by precipitation of Mo or W, and for reduction of the tritium inventory by enhancing the reaction from $\mathrm{T}_{2}$ to $\mathrm{TF}$ which is more soluble in Flibe.

Fig. 1 is a schematic illustration of the REDOX control by $\mathrm{WF}_{6}$ doping into Flibe. The reaction of the doped $\mathrm{WF}_{6}$ with $\mathrm{T}_{2}$ results in extremely biased equilibrium of TF over $\mathrm{T}_{2}$. At the wall surface, the reaction of $\mathrm{WF}_{6}$ with $\mathrm{V}$ results in dissolution of $\mathrm{V}$ into Flibe and plating of the wall surface with $\mathrm{W}$. The $\mathrm{W}$ plating is thought to be effective as a corrosion barrier for the wall. In addition, the plating has a self-healing capability. The present study investigated possible tritium management scenario by quantitative thermodynamic calculations.

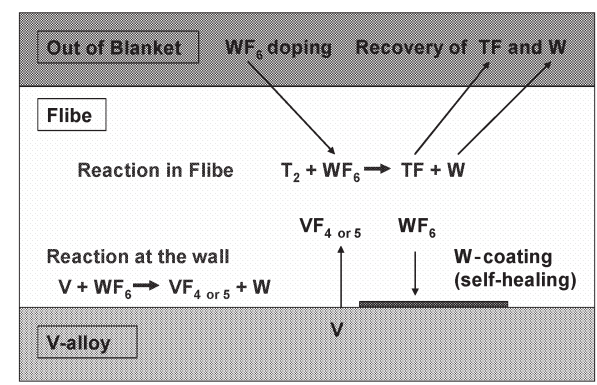

Fig. 1 Schematic illustration of REDOX control of Flibe by doping $\mathrm{WF}_{6}$.

The reaction of $\mathrm{WF}_{6}$ with $\mathrm{T}_{2}$ is given as follows.

$$
1 / 6 \mathrm{WF}_{6}+1 / 2 \mathrm{~T}_{2}=1 / 6 \mathrm{~W}+\mathrm{TF}
$$

For this reaction, the chemical equilibrium equation at temperature $\mathrm{T}$ is given by

$$
\Delta \mathrm{G}_{\mathrm{f}}{ }^{\mathrm{o}}=-\mathrm{RT} \ln \mathrm{P}_{\mathrm{TF}} / \mathrm{P}_{\mathrm{WF} 6}{ }^{1 / 6} \mathrm{P}_{\mathrm{T} 2}{ }^{1 / 2}
$$

here $\Delta \mathrm{G}_{\mathrm{f}}^{0}, \mathrm{R}, \mathrm{P}_{\mathrm{TF}}, \mathrm{P}_{\mathrm{WF} 6}$ and $\mathrm{P}_{\mathrm{T} 2}$ are the difference in the free energy for fluoride formation, gas constant, partial pressure of $\mathrm{TF}, \mathrm{WF}_{6}$ and $\mathrm{T}_{2}$, respectively.

For evaluation of tritium inventory in the $\mathrm{V}-4 \mathrm{Cr}-4 \mathrm{Ti}$, the blanket structure of FFHR-FV was assumed, where the breeding blanket is composed of 700 tons of V-4Cr-4Ti structure, 1140 tons of Flibe, and neutron/thermal shield.
Fig. 2 shows partial pressure and tritium molar fraction of $\mathrm{TF}$ and $\mathrm{T}_{2}$ in various levels of $\mathrm{MoF}_{6}$ or $\mathrm{WF}_{6}$ doping into Flibe. In the figure, tritium inventory in $\mathrm{V}-4 \mathrm{Cr}-4 \mathrm{Ti}$ structure and in Flibe were also indicated assuming FFHR-FV blanket structure. It should be noted that the tritium inventory in $\mathrm{V}-4 \mathrm{Cr}-4 \mathrm{Ti}$ structure and in Flibe are dominated by the partial pressure of $T_{2}$ and concentration of TF in Flibe, respectively.

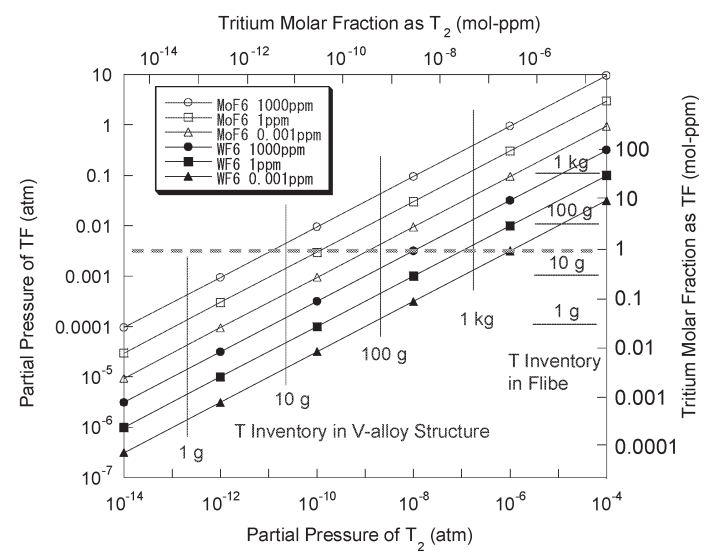

Fig. 2 Partial pressure and tritium molar fraction of TF and $\mathrm{T}_{2}$ in Flibe for various levels of $\mathrm{MoF}_{6}$ or $\mathrm{WF}_{6}$ doping into Flibe at $1000 \mathrm{~K}$. Tritium inventory in $\mathrm{V}-4 \mathrm{Cr}-4 \mathrm{Ti}$ structure and in Flibe were also indicated assuming FFHR-FV blanket structure.

The level of TF in Flibe is a key parameter for the tritium management in the system. The tritium inventories in 700 tons of $\mathrm{V}-4 \mathrm{Cr}-4 \mathrm{Ti}$ structure and 1140 tons of Flibe in the blanket area were compared in Fig. 3 as a function of the tritium molar fraction as TF in Flibe in two cases of $\mathrm{MoF}_{6}$ and $\mathrm{WF}_{6}$ doping.

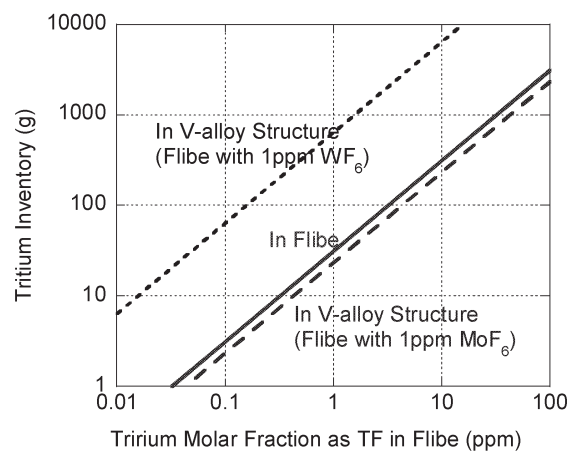

Fig. 3 The tritium inventories in $\mathrm{V}-4 \mathrm{Cr}-4 \mathrm{Ti}$ structure and Flibe in the blanket area as a function of the tritium molar fraction as TF in Flibe at $1000 \mathrm{~K}$. The blanket structure of FFHR-FV was assumed, which is composed of 700 ton of V-4Cr-4Ti structure and 1140 ton of Flibe.

Assuming the guideline of the total tritium inventory in the blanket area of $100 \mathrm{~g}$, the acceptable maximum level of TF in Flibe can be estimated to be $\sim 3 \mathrm{ppm}$ and $\sim 0.1 \mathrm{ppm}$ for $\mathrm{MoF}_{6}$ and $\mathrm{WF}_{6}$ doping, respectively. According to the previous analysis of tritium management, in which tritium level in Flibe was designed to be $\sim 0.1 \mathrm{ppm}$, the $\mathrm{WF}_{6}$ doping seems to be feasible for the tritium management. 